UCRL-ID-130754

\title{
Cutting Fluid Study for Single Crystal Silicon
}

\author{
David Chargin
}

May 5, 1998

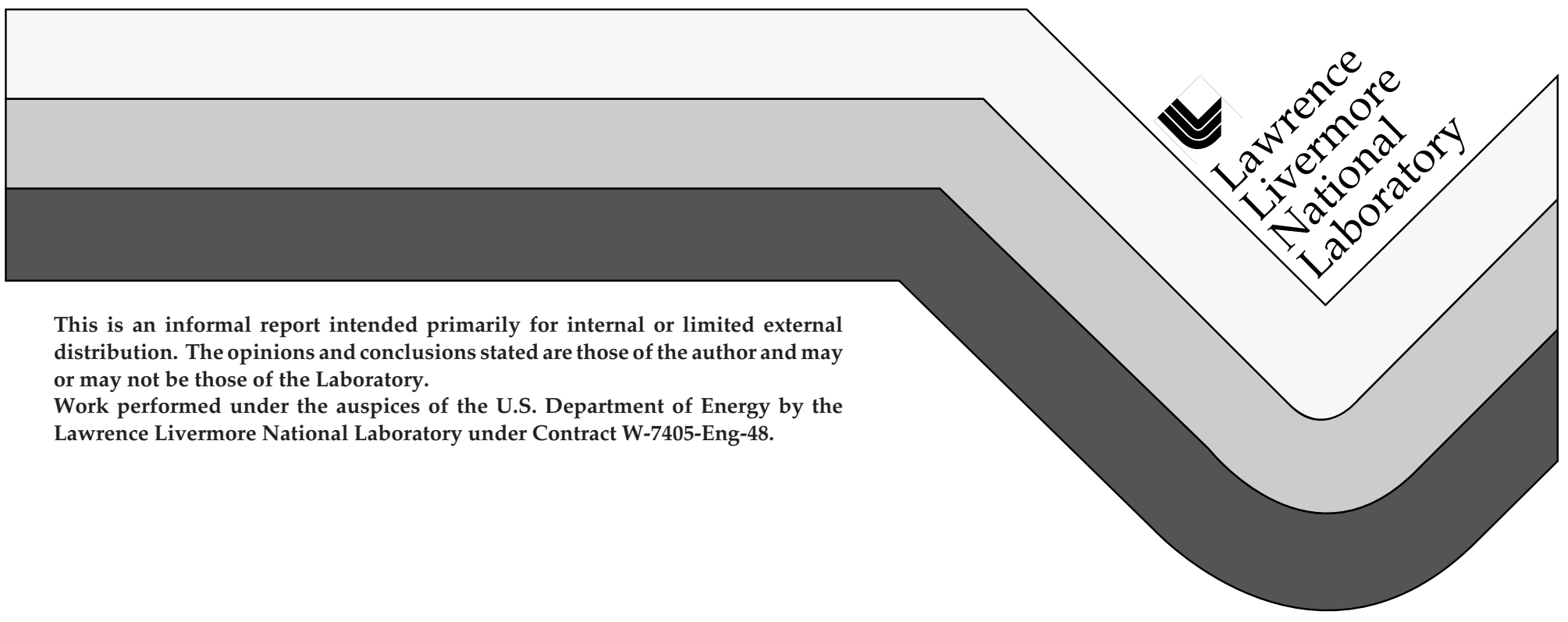




\section{DISCLAIMER}

This document was prepared as an account of work sponsored by an agency of the United States Government. Neither the United States Government nor the University of California nor any of their employees, makes any warranty, express or implied, or assumes any legal liability or responsibility for the accuracy, completeness, or usefulness of any information, apparatus, product, or process disclosed, or represents that its use would not infringe privately owned rights. Reference herein to any specific commercial product, process, or service by trade name, trademark, manufacturer, or otherwise, does not necessarily constitute or imply its endorsement, recommendation, or favoring by the United States Government or the University of California. The views and opinions of authors expressed herein do not necessarily state or reflect those of the United States Government or the University of California, and shall not be used for advertising or product endorsement purposes.

This report has been reproduced directly from the best available copy.

Available to DOE and DOE contractors from the Office of Scientific and Technical Information P.O. Box 62, Oak Ridge, TN 37831

Prices available from (423) 576-8401

Available to the public from the National Technical Information Service

U.S. Department of Commerce 5285 Port Royal Rd., Springfield, VA 22161 


\title{
Cutting Fluid Study for Single Crystal Silicon ${ }^{\dagger}$
}

\author{
David Chargin \\ Lawrence Livermore National Laboratory \\ Livermore, CA
}

\begin{abstract}
Summary:
An empirical study was conducted to evaluate cutting fluids for Single Point Diamond Turning (SPDT) of single crystal silicon. The $\mathrm{pH}$ of distilled water was adjusted with various additives to examine the effect of $\mathrm{pH}$ on cutting operations. Fluids which seemed to promote ductile cutting appeared to increase tool wear as well, an undesirable tradeoff. High pH sodium hydroxide solutions showed promise for further research, as they yielded the best combination of reduced tool wear and good surface finish in the ductile regime. Negative rake tools were verified to improve the surface finish, but the negative rake tools used in the experiments also showed much higher wear than conventional $0^{\circ}$ rake tools. Effects of crystallographic orientation on SPDT, such as star patterns of fracture damage forming near the center of the samples, were observed to decrease with lower feedrates. Silicon chips were observed and photographed, indicative of a ductile material removal process.
\end{abstract}

\section{Experimental Setup:}

An experimental setup was selected to evaluate cutting fluids for the SPDT of silicon in the ductile regime. All machining was performed on the PERL-2 (Precision Engineering Research Lathe) at Lawrence Livermore National Laboratory, a horizontal spindle T-base lathe with microinch precision. Tools manufactured with a $1.52 \mathrm{~mm}$ nose radius and $0^{\circ}$ rake angle were used for most tests, while tools provided by a different manufacturer with negative rake angles were also evaluated. Four test samples of single crystal silicon, $95 \mathrm{~mm}$ in diameter and $12.7 \mathrm{~mm}$ thick with surface normals in the [100] direction, were vacuum chucked in the PERL-2 machine to 380 $\mathrm{mm} \mathrm{Hg}$. Cutting fluid delivery was accomplished with a tank pressurized by compressed air, pushing the fluid out a $0.254 \mathrm{~mm}$ diameter nozzle. The cutting fluid was directed at the intersection of the tool tip and sample, adjusted so the flow was between 2-3 liters per hour. The machine is enclosed, and both the spindle and enclosure are regulated to $20 \pm 0.5^{\circ} \mathrm{C}$.

\section{Test Procedure:}

Cutting parameters for the tests were chosen based on past experience for a ductile finishing cut. No special surface preparation, i.e. chemical etching to remove micro-fracture damage, was performed between tests. It was felt that 3 roughing cuts would be sufficient to level the surface of the sample and insure a repeatable surface between final cuts. Samples were machined from the inside out, shielding the tool from slow cutting speeds near the center when it is dull at the end of the cut, the centers of each disk previously having been relieved of material.

For the initial experiments, final cut parameters included: spindle speed $1000 \mathrm{rpm}$, feedrate $1.91 \mu \mathrm{m} / \mathrm{rev}$, and cutting depth $2.54 \mu \mathrm{m}$. This gave a cutting distance of $3.7 \mathrm{~km}$ and a cutting speed of $5 \mathrm{~m} / \mathrm{sec}$ at the outer edge. Roughing cuts used identical parameters but with a feedrate of $2.54 \mu \mathrm{m} / \mathrm{rev}$. A second set of experiments then lengthened the cutting distance in the hope of accentuating the differences in the cutting fluids. Cutting parameters were the same, with the exception of the feedrate, which was decreased to $1.27 \mu \mathrm{m} / \mathrm{rev}$ from $1.91 \mu \mathrm{m} / \mathrm{rev}$. This increased the cutting distance to $5.6 \mathrm{~km}$. The lower feedrate should increase the ductility of the cut, and improve the initial surface finish. Spindle speed and depth of cut remained at $1000 \mathrm{rpm}$ and $2.54 \mu \mathrm{m}$ respectively, and the roughing procedure was also unchanged.

\section{Results:}

Cutting fluids to test were then chosen for several reasons. First, the $\mathrm{pH}$ of the cuttings fluids was to be varied, as it should affect the silicon dioxide layer on the surface of the silicon. The semiconductor industry has had success with using alkaline solutions in polishing silicon ${ }^{3}$. A surfactant was chosen to find the influence of surface tension. Several other fluids, such as $25 \%$ ethylene glycol solution, were then also tested based on reports of success at other sites. 
Initial baseline tests were run with distilled water which was approximately $\mathrm{pH}$ 6.0. Three tests established the baseline roughness and wear values seen in Table 1. Further tests were then conducted to evaluate the effectiveness of various water based cutting fluids. Ammonium hydroxide was added to the water to form an alkaline solution with $\mathrm{pH}$ 10.0. Surface roughness ranged from equivalent to worse than baseline. Tool wear was just appreciably greater than the baseline, not giving much hope for alkaline solutions. Castrol Safety-Cool 822C, a cutting fluid additive for water, produced slightly better surface finishes than water, but with more tool wear. A surfactant, ACTST5, was then used to examine the effects of surface tension on cutting fluid effectiveness. Two runs conducted with this solution produced nearly identical results to the baseline distilled water. For several of these tests, a cloudy four axis pattern appeared at the centers of the samples, consistent with past experiences of machining crystals grown in the [100] direction.

A non-water based cutting fluid was then evaluated, Shell Diala Oil AX. This oil greatly increased the wear on the tool and produced a much worse surface finish. Tool wear increased to $130-250 \mathrm{~nm}$. Roughness values at the outer edge were nearly three times that of the baseline water, at $150 \AA$ RMS. A second test was then run with a new nozzle on the fluid delivery system. This nozzle was $0.51 \mathrm{~mm}$ in diameter and angled in from the feed side of the tool, making a $15^{\circ}$ angle with the test sample. The fluid was directed in at the side of the tool/chip interface, opposite the direction of feed. This fluid delivery setup greatly reduced the tool wear, down to $64 \mu \mathrm{m}$. However, the surface roughness also increased considerably, to $354.5 \AA$ RMS at the outer edge. Future tests utilized the previous delivery system.

The final test of this initial study evaluated the negative rake tools. Three tools were provided, having rakes of $-1^{\circ},-$ $15^{\circ}$, and $-30^{\circ}$. The tools did demonstrate the value of negative rakes, as the surface finish did improve with the increasing negative rake. The $-30^{\circ}$ tool also did not leave any stars or other crystallographic artifacts in the test sample. However, these tools did show much more tool edge recession than the conventional tools, about 100$150 \mathrm{~nm}$.

The new feedrate in the second set of tests greatly increased the tool wear in the distilled water baseline, up to $280 \mathrm{~nm}$ from the previous baseline of $20-50 \mathrm{~nm}$. The surface finish, however, did not improve significantly, not even near the beginning of the cut, and was worse in the outer areas. Investigation of the effect of $\mathrm{pH}$ continued, now with a low $\mathrm{pH}$ solution. A 5\% solution of acetic acid (commercial grade vinegar) was used with a $\mathrm{pH}$ of 2.4. Other water based cutting fluids consisted of ethylene glycol, Wafermate 1000 (a propylene glycol solution used in the semiconductor industry), the ACT-ST5 surfactant, Trim Clear (a commercial cutting fluid additive), and sodium hydroxide. These solutions were all generally alkaline, with the exception of the ethylene glycol, which close to neutral. While these solutions generally did not appreciably improve the measured parameters, scattered patches of fracture damage, visible optically, were substantially reduced in the ethylene glycol, acetic acid, sodium hydroxide, and Wafermate 1000 solutions. Increases in surface roughness were appeared to be entirely attributable to feed marks.

Sodium hydroxide proved to be the most interesting cutting fluid. It was used in a $0.005 \%$ solution with a $\mathrm{pH}$ of 11. The first trial resulted in tool wear quite comparable to the water at $180 \mathrm{~nm}$, and the finish actually improved towards the outer edge, unlike any of the other tests. Further tests were run with extended baths in the cutting fluid prior to cutting. During the second test, tool wear increased to $230 \mathrm{~nm}$, but the surface finish improved even more, giving the best overall finish of the study. Unfortunately, during the third test, the first $20 \mathrm{~mm}$ was machined at a higher feedrate, $2.54 \mu \mathrm{m} / \mathrm{rev}$, and lower cutting speed, because of an operator error. Lower wear was expected because of the higher feedrate, but it strangely increased to the highest measured wear, $550 \mathrm{~nm}$.

Two interesting anomolies during testing included silicon chips and tool chatter. Curly silicon chips were observed after several cuts. These were observed and photographed through optical microscopes clinging to the test sample

$\dagger$ This work was performed under the auspices of the U.S. DOE by Lawrence Livermore National Laboratory, Livermore, California under Contract No. W-7405-Eng-48.

$\ddagger$ Currently at the Massachusetts Institute of Technology, Cambridge, MA 
after the cut. These chips are indicative of the ductile cutting taking place, and varied greatly in size, which was not quantitatively measured. This difference in size is probably due to the amount of fracture taking place varying as the crystal is rotated through different orientations. Chips were probably formed in all of the final cuts, but collecting them does not appear to be a repeatable process with the horizontal spindle, as they are washed with the cutting fluid and destroyed. A chatter phenomenon of unknown origin was observed during several roughing cuts and one final cut. The chatter was audible and estimated at $17 \mathrm{khz}$ from the pattern in the finished part. The spindle speed could be varied and the pitch would rise and fall with spindle speed, even if the feed was stopped. Talystep scans indicate the peak to valley measurement of the hills to be $\sim 200 \mathrm{~nm}$. This chatter helps account for the high surface roughness in one ethylene glycol test. 


\section{Table 1}

Test Data $-75 \mu_{\text {in/rev. Final Cut }}$

\begin{tabular}{|c|c|c|c|c|c|c|}
\hline \multirow[t]{2}{*}{ Cutting Fluid } & \multirow[t]{2}{*}{$\mathrm{pH}$} & \multirow{2}{*}{$\begin{array}{c}\text { Tool Wear } \\
\text { (nm) }\end{array}$} & \multicolumn{3}{|c|}{ Surface Roughness (Å RMS) } & \multirow[t]{2}{*}{ Notes } \\
\hline & & & Radius 5mm & Radius $25 \mathrm{~mm}$ & Radius 46mm & \\
\hline Distilled Water & 6.0 & 20 to 50 & 29.1 & 33.1 & 30.3 & star \\
\hline Distilled Water & 6.0 & chip & 22.7 & 50.4 & 61.6 & \\
\hline Distilled Water & 6.0 & $>50$ & 16.3 & 50.9 & 51.7 & \\
\hline Ammonium Hydroxide & 10.0 & $>50$ & 37.0 & 56.8 & 96.1 & \\
\hline Ammonium Hydroxide & 10.5 & 50 to 80 & 30.2 & 40.2 & 58.3 & \\
\hline Castrol $822 \mathrm{C}$ & 9.5 & 75 & 19.2 & 34.2 & 40.5 & star \\
\hline ACT-ST5 & 8.3 & 20 to 50 & 26.0 & 31.4 & 53.3 & star \\
\hline ACT-ST5 & 6.0 & $>20$ & 22.5 & 32.4 & 50.5 & star \\
\hline Shell Diala Oil AX & NA & 130 to 250 & 35.0 & 105.6 & 150.2 & \\
\hline Shell Diala Oil AX & NA & 65 & 19.8 & 108.8 & 354.5 & angled nozzle \\
\hline Edge Tech. Tool $-1^{\circ}$ & 9.5 & 130 to 150 & 20.5 & 55.0 & 71.2 & star \\
\hline Edge Tech tool $-15^{\circ}$ & 9.5 & 100 to 130 & 27.9 & 42.7 & 55.4 & star \\
\hline Edge Tech tool $-30^{\circ}$ & 9.5 & 100 to 130 & 11.8 & 33.9 & 47.7 & \\
\hline
\end{tabular}

\section{Table 2}

Test Data - $50 \mu$ in./rev. Final Cut

\begin{tabular}{|c|c|c|c|c|c|c|}
\hline \multirow[t]{2}{*}{ Cutting Fluid } & \multirow[t]{2}{*}{$\mathrm{pH}$} & \multirow{2}{*}{$\begin{array}{c}\text { Tool Wear } \\
\text { (nm.) }\end{array}$} & \multicolumn{3}{|c|}{ Surface Roughness (Å RMS) } & \multirow[t]{2}{*}{ Notes } \\
\hline & & & Radius 5mm & Radius $25 \mathrm{~m}$ & Radius 46mm & \\
\hline Distilled Water & 6.0 & 150 & 24.9 & 26.8 & 53.1 & Si Chips \\
\hline Distilled Water & 6.0 & 150 to 180 & 18.0 & 30.6 & 142.1 & \\
\hline $5 \%$ Acetic Acid & 2.4 & 150 to 180 & 34.3 & 35.7 & 54.8 & \\
\hline $5 \%$ Acetic Acid & 2.4 & 280 & 25.8 & 51.1 & 89.5 & \\
\hline 1:200 Ethylene Glycol & 6.2 & 280 & 18.8 & 30.4 & 72.7 & Si Chips \\
\hline $25 \%$ Ethylene Glycol & 6.3 & 230 & 18.7 & 32.0 & 163.2 & \\
\hline 25\% Ethylene Glycol & 6.2 & 250 to 280 & 47.3 & 49.8 & 563.4 & \\
\hline Sodium Hydroxide & 10.9 & 180 & 20.0 & 64.4 & 40.9 & \\
\hline Sodium Hydroxide & 11.0 & 230 & 33.5 & 52.5 & 32.1 & Si Chips, Best overall finish \\
\hline Sodium Hydroxide & 11.0 & 550 & 39.1 & 51.2 & 44.5 & Si Chips in $100 \mu$ in/rev region \\
\hline $25 \%$ Wafermate 1000 & 8.7 & 250 & 27.9 & 40.8 & 55.3 & \\
\hline ACT-ST5 & 7.8 & 240 & 23.8 & 41.9 & 58.4 & Si chips in roughing cuts \\
\hline ACT-ST5 & 7.8 & 220 & 29.2 & 44.3 & 82.3 & \\
\hline 1\% Trim Clear & 9.5 & 150 to 180 & 45.0 & 30.2 & 60.1 & \\
\hline
\end{tabular}




\section{Discussion and Conclusions:}

Lower feedrates reduced the effects of crystallographic orientation. Star shaped patterns and cloudy areas common to the $1.91 \mu \mathrm{m} / \mathrm{rev}$ feedrate disappeared when the feedrate was lowered to $1.27 \mu \mathrm{m} / \mathrm{rev}$. This is consistent with the results produced in previous studies, which found different critical chip thicknesses for different crystal orientations. The star-shaped patterns themselves followed the 4 or 2 fold symmetry caused by the intersection of planes in a crystal grown in the [100] direction. Strangely, such patterns would be revealed during a roughing cut and sometimes would not reappear during a subsequent roughing cut, even though it may have used the same tool edge and cutting parameters.

Negative rake tools confirmed the value of negative rake angles in improving surface finish. However, these tools had much higher wear rates than the conventional tools, lessening their usefulness. This is contrary to other reports showing the negative rake tools provided extended life ${ }^{1}$. The high wear rate may possibly be associated with the geometry of the cutting with the negative rake angle. In any case, the high wear would be unacceptable over the distances necessary for cutting larger parts.

No cutting fluid reduced tool wear over that of distilled water. The one non-water based fluid tested, Shell Diala Oil AX, proved to be inferior to distilled water in all respects. Generally, cutting fluids reducing the wear on the tool also increased the fracture damage in the sample, but still maintained low roughness values. Those cutting fluids that resulted in higher tool wear also appeared to enhance ductile cutting. There was often little or no apparent fracture damage, and the high roughness values were caused solely by the feed marks. The higher wear on some fluids may also be attributed to a more consistent depth of cut. The water provides evaporative cooling, which can affect the depth of cut as the workpiece retracts away from the tool. More thermally stable fluids might then suffer from higher wear, although they may encourage better figure accuracy. This effect was not quantified or measured here.

The sodium hydroxide cutting fluid was the only deviation from these observations. While it did exhibit higher tool wear in some tests, it was the only cutting fluid to demonstrate an improvement in surface finish as the tool wore. This improvement in the outer region is probably due to longer exposure time, as the spinning disk sends the cutting fluids to the outside. These results are most probably due to the high $\mathrm{pH}$ of the cutting fluid interacting with the $\mathrm{SiO}_{2}$ layer on the surface, although it is not beyond possibility that the sodium itself had an effect. Other high $\mathrm{pH}$ fluids had much higher concentrations of other molecules, which may have affected the cutting process. The report recommending a 25\% ethylene glycol solution may have used antifreeze as a source of the ethylene glycol, which has a much higher $\mathrm{pH}$ ( $\mathrm{pH} 10.2$ in one sample tested.) This could have given the better results reported.

Cutting speed, not thought to be an important parameter in SPDT, may have greater effects when cutting fluid action is taken into account. The high tool wear experienced in the third sodium hydroxide test runs counter to the expectation of less wear due to higher feedrate. The low cutting speed may have been the cause of this effect.

One possibility is that water is an ideal cutting fluid for SC silicon. It has a very small molecule with a high dipole moment, which causes the molecules to clump together. The small molecular size may allow easier penetration to the cutting interface, while the dipole moment may enhance the lubricating action as the particles stick together ${ }^{2}$. This does not address the concerns of the thermal effects of water, which were not quantified here. Evaporative cooling from the cutting fluid can significantly distort the part to be manufactured ${ }^{4}$. A compromise solution might be developed that may reduce the thermal effects at the expense of a small amount of tool wear

\section{References:}

1. Buelow, Larry, et al, "Resonator Optics Materials Assessment - Technical Status Report 1992-1993", Martin Marietta Technologies, Inc.

2. Estabrook, Dr. Kent, LLNL

3. Shimura, Fumio, Semiconductor Silicon Crystal Technology. San Diego: Academic Press, 1989 
4. Taylor, J. S, Syn, C. K., Donaldson, R. R., and S. Shimada, "Ductile-Brittle Transition of Cutting Behavior in Diamond Turning of Single Crystal Si", Lawrence Livermore National Laboratory 



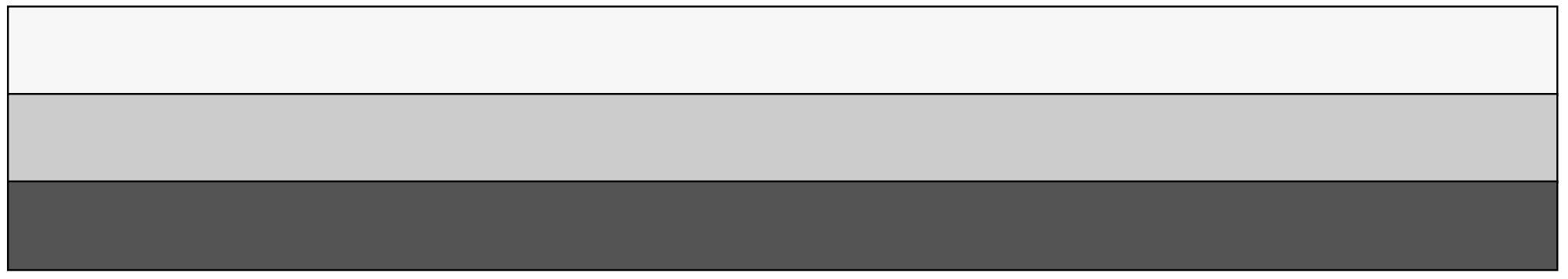

